we get a different sample of numbers ${ }^{3}$, and secondly the pollen grains grow differently, so that the most unbalanced grains are disproportionately small ${ }^{2}$.

Two examples of the resting stage action of the chromosomes are of specific genetic importance. In the hybrid Enothera species, the nucleus which, on account of its position, is expected to produce the embryo-sac, fails to divide if it has a certain femaledefective genetic constitution. A nucleus of the opposite type (segregated from it at meiosis) then divides and takes on its function*. On the other hand, in Rhoeo discolor pollen grains are formed not only with the haploid 6 chromosomes but also, owing to non-disjunction, with 5 and 7 . Those with 7 come to division, those with 5 being genetically defective do not ${ }^{3}$. This indeed is a rule to which only one exception is known. In spite of the frequency with which defective pollen grains are known to be formed at meiosis, only once has such a pollen grain been observed to reach mitosis, and this pollen grain was in the exceptional state of having remained attached to a complementary sister grain of the meiotic tetrad ${ }^{5}$.

The evidence of the genetic individuality of cells raises another problem: How far is the choice of egg cell amongst the genetically different products of meiosis genetically determined, as it is in Enothera ? We know that the position of the embryo-sac cell is variable both where there are several mother cells, as in Euphorbia, and where there is only one, as in Culcitium $^{6}$. We know also that the determination takes place after meiosis. We can therefore scarcely doubt that where important genetic differences distinguish the products of meiosis (as in triploids and structural hybrids), there will be a natural selection of favourable combinations in the egg cells. It remains to say that, where all the products of meiosis are not separated by cell walls (as in the Lilium and Scilla types of embryo-sac), it is impossible to decide from direct observation alone whether the egg-cell is not sometimes genetically instead of positionally determined. Breeding tests will be necessary. This is a question worth deciding, because selective fertilization in the wasp Habrobracon ${ }^{7}$ indicates that separate nuclei within a single cell are capable of showing by their movements a genetic individuality distinct from that of the cell as a whole.

That the interface or monomolecular film which separates the nucleus from the cytoplasm protects it from mere dispersion and violent external fluctuations is obvious. That in doing so it acts as a semipermeable membrane may be shown in various ways ${ }^{3}$. But that it could utterly preclude chemical intercourse and therefore genetic action between the outside and the inside is contradicted every time the nucleus of an egg divides on the stimulus of a sperm ; for if the nucleus cannot act on the cytoplasm outside, how can agents outside act on it, determining its division or its death?

John Innes Horticultural Institution, C. D. Darlington. Merton, S.W.19. Oct. 30 .

1 Nature, 140, 770 (1937).

2 Darlington, C. D., "Chromosome Behaviour and Structural Hybridity in the Tradescantiæ", J. Genet., 21, 207-286 (1929).

${ }^{3}$ Darlington, C. D., "The External Mechanics of the Chromosomes, ${ }^{3}$ Darlington, C. D., “The External Mechanic
I-V”, Proc. Roy. Soc., B, 121, 264-319 (1936).

- Renner, O., "Heterogamie im weiblichem Geschlecht und Embryosackentwicklung bei den Onotheren", $Z$. Bot., 13, 609-621 (1921).

s Belling, J., "The Origin of Chromosomal Mutations in Uvularia, J. Genet., 15, 245-266 (1925).

'Schnarf, K., "Embryologie der Angiospermen", Hb. Pflanzenanat., 10 (1929).

"Whiting, P. W., "Sex Determination in Bees and Wasps", $J$. Hered., 28, 263 (1935).

\section{Germination of Resistant Spores of Blastocladia Pringsheimii}

LETTERS ${ }^{1}$ have appeared in NATURE relating to the germination of resistant spores, and in them certain suggestions have been put forward as to the needs of such spores. With these in mind, controlled conditions have been found suitable for the germination of the supposedly resistant resting spores of Blastocladia Pringsheimii Reinsch. The lack of success of former attempts to germinate them is perhaps due to the use of spores either immature or desiccated. A simple method has been found of storing the spores so that they may have time to mature and yet not become desiccated, or lost, meanwhile.

Blastocladia Pringsheimii Reinsch can be grown in the laboratory on small tomatoes in a jar of water. This fruit is particularly satisfactory, as the skin is thin and transparent and can easily be removed bearing the fungus in situ. Fruits were inoculated in April and again in May of this year, and as soon as young plants of the fungus were observed growing on them (with the mycelium ramifying within the pulp of the fruit and the sporangia emergent in the water) the fruits were well washed in fresh water daily to keep down the bacteria. In June the fungus, now bearing a good crop of resting spores, was stored: the fruit skin bearing the fungus was torn into pieces which naturally rolled up, the outer side within the roll, so that the fungus, with such spores as still remained attached, was conveniently held within the roll of skin. Small flasks were taken and plain agar agar poured in, to a depth of half an inch. When this had set, the rolls of skin were placed on the surface and more agar agar was poured upon them to a depth of half an inch, making one inch depth all told. These flasks were left in the laboratory until September, when the pieces of skin were taken out and unrolled, exposing the mature, but not desiccated, spores. These germinated in water in about 24 hours. Other pieces of fruit skin were unrolled from time to time throughout October and into November, and a good percentage of the spores always germinated readily in water within a day or so.

This is not the place in which to describe the phenomena of germination and the habit of the germlings, an account of which will, it is hoped, appear shortly in a botanical journal.

Elrzabeth Blackwell.

Royal Holloway College,

Englefield Green,

London. Nov. 16.

${ }^{1}$ NATURE, 135, 306 (Feb. 23, 1935); 135, 546 (April 6, 1935); 139, 758 (May 1, 1937)

\section{Photodynamic Action of Carcinogenic Agents}

IN a recent communication ${ }^{1}$, we described the photosensitization of white mice by four carcinogenic agents. Since then we have sought other ways of demonstrating this reaction quickly, and have found that Paramecium is an excellent test object.

When benz-pyrene is ground up with tap water, and then spun for half an hour at 2,000 revs., a slightly opalescent liquid results containing not more than one part in 10,000. Paramecia will live in this in the dark for many days, but when placed in a glass cell, opaque to radiation of wave-length less than $3500 \mathrm{~A}$., in sunlight or in front of a mercury 